\title{
AMBIENTES VIRTUAIS DE APRENDIZAGEM NA EDUCAÇÃO PRESENCIAL: UMA PERSPECTIVA SÓCIO-HISTÓRICA PARA A ENSINAGEM DE LINGUAGENS
}

\author{
Caio Henriques Sica Lamas ${ }^{1}$ \\ Marcel Alvaro de Amorim²
}

\begin{abstract}
Resumo: Na tentativa de transformar as práticas de ensinagem em um recém-implantado curso Técnico em Informática para a Internet, concretizou-se a implementação de atividades em Ambiente Virtual de Aprendizagem (AVA) - Moodle - como apoio ao ensino presencial, intencionando, a partir de uma perspectiva sócio-histórica da linguagem e da aprendizagem, intensificar a interação dialógica entre o conhecimento prévio dos alunos e os novos saberes a serem construídos na sala de aula. Nesse contexto, o objetivo deste artigo é ponderar sobre o primeiro semestre de implementaçáo dessa prática no curso mencionado, analisando especificamente o modo como o Moodle foi utilizado nas disciplinas Web Design e Inglês Instrumental. Metodologicamente, realizar-se-á uma Análise Dialógica do Discurso das salas de aula virtuais dessas disciplinas, bem como dos discursos dos professores e alunos que se envolveram nessa experiência. Os resultados da pesquisa sinalizam as dificuldades encontradas pelos professores das disciplinas mencionadas na tentativa de operacionalizar a base teórico-metodológica sócio-histórica na seleção de materiais e construção das atividades que integram o AVA.
\end{abstract}

Palavras-chave: Ambiente virtual de aprendizagem; Moodle; Teoria sócio-histórica.

\section{VIRTUAL LEARNING ENVIRONMENTS IN FACE TO FACE EDUCATION: A SOCIO-HISTORICAL PERSPECTIVE FOR LANGUAGES TEACHING-AND-LEARNING}

\begin{abstract}
In an attempt to transform the teaching-and-learning practices of a recently implemented Vocational Course on Computing for Internet, a Virtual Learning Environment (VLE) - Moodle was implemented as support to face to face teaching-and-learning in order to intensify the dialogical
\end{abstract}

1 Mestre em Design. Professor e pesquisador do Instituto Federal do Rio de Janeiro campus Sáo João de Meriti.

2 Doutor em Linguística Aplicada. Professor e pesquisador do Instituto Federal do Rio de Janeiro campus São João de Meriti e do Programa Profissional em Educação Profissional e Tecnológica ProfEPT - do Instituto Federal do Rio de Janeiro campus Mesquita. 
interaction between student's prior knowledge and new knowledge to be constructed in the classroom from a socio-historical perspective of language and teaching-and-learning. In this context, this paper aims at reflecting on the first semester of implementation of this practice in the above-mentioned course, specifically analyzing the way Moodle was used in Web Design and English for Specific Purposes disciplines. Methodologically, a Dialogical Discourse Analysis of the virtual classrooms of these subjects as well as of the discourses constructed by the teachers and students who were involved in this experience was performed. The results of the research point out to the difficulties encountered by the teachers of the mentioned subjects in the attempt to operationalize the sociohistorical theoretical and methodological basis in the selection of materials and construction of the activities that integrate the VLE.

Keywords: Virtual learning environment, Moodle, Socio-historical theory.

\section{Introduçáo}

O alcance das tecnologias digitais é cada vez mais abrangente nos diversos setores da sociedade brasileira. Na medida que a Internet se populariza, as Tecnologias da Informação e Comunicação (TICs) se fazem presentes cotidianamente através de diferentes dispositivos, como computadores, smartfones, tablets etc. A influência das TICs também já é manifesta no cenário educacional. Huertas (2007) sinaliza que, quando utilizadas na educação, as TICs implicam em novas necessidades educacionais e em diferentes possibilidades metodológicas, o que traz consigo a exigência de ressignificação de todo o processo de ensinagem $^{3}$. Selim (2007) afirma ainda que, na segunda década do século XXI, ao propormos novas abordagens para o processo educativo, devemos incluir a dimensão tecnológica como um importante fator a ser considerado.

Nesse sentido, durante o planejamento das práticas de ensinagem do recémimplantado curso Técnico em Informática para a Internet de um instituto federal localizado na Baixada Fluminense do estado do Rio de Janeiro, concretizou-se a implementação de atividades em Ambiente Virtual de Aprendizagem (AVA) - nesse caso, o Moodle - como apoio ao ensino presencial, intencionando, a partir de uma perspectiva socio-histórica da linguagem e da aprendizagem (BAKHTIN, 2016; VOLÓCHINOV, 2017; VYGOTSKY, 2007), intensificar a interação dialógica entre o contexto sócio-histórico, o conhecimento prévio dos alunos e os novos saberes a serem construídos na sala de aula.

Dessa forma, foi proposto que cada disciplina do curso em questão tivesse a sua disposição uma sala de aula no AVA mencionado. Além disso, foi proposto também que a sala de aula virtual deveria funcionar como uma expansão da sala de aula presencial; em termos práticos, ao professor caberia (1) inserir, antes da aula, materiais - vídeos, textos etc. - que provocassem a ativação de conhecimentos prévios dos educandos; (2) conduzir as discussôes na sala de aula presencial a partir dos materiais disponibilizados previamente em diálogo com outros entregues em

3 Seguindo Nicolaides e Szundy (2013), utilizamos o termo ensinagem na tentativa de demarcar a profunda imbricação entre as práticas de ensino-e-aprendizagem 
aula; e (3) propor, após a aula, espaços para interaçáo entre os alunos ou entre alunos e professores no ambiente virtual, tais como fóruns, chats etc.

Nesse contexto, o objetivo deste artigo é ponderar sobre o primeiro semestre de implementação dessa prática no curso mencionado, analisando especificamente o modo como o Moodle foi organizado e utilizado nas disciplinas Web Design e Inglês Instrumental, que fazem parte do núcleo de linguagens do curso. Metodologicamente, realizar-se-á uma Análise Dialógica do Discurso (BRAIT, 2004; SOBRAL e GIACOMELLI, 2016) das salas de aula virtuais dessas disciplinas, bem como de discursos dos professores e alunos que se envolveram nessa experiência durante o semestre em que ocorreu a investigaçáo, procurando compreender de que modo os pressupostos teóricos que embasavam o projeto - a filosofia da linguagem e a teoria da aprendizagem sócio-históricas - eram ressignificados na prática pedagógica dessas duas disciplinas.

Para tanto, este artigo organiza-se em mais quatro seçôes. Na primeira, apresentamos os pressupostos teóricos da filosofia da linguagem do Círculo de Bakhtin e os apontamentos da teoria da aprendizagem-e-desenvolvimento vygostskyana. Na segunda seção, apresentaremos a metodologia da pesquisa realizada. Já na terceira seção, apresentamos a análise propriamente dita, a partir de um corpus formado pelas salas de aula virtuais das disciplinas mencionadas, pelos diários de pesquisador dos professores das disciplinas e por depoimentos online de alunos sobre a experiência.

\section{A construçáo do conhecimento sobre a ótica sócio-histórica}

Nas seçôes subsequentes, teceremos um quadro mais amplo que se inicia com a descrição dos principais conceitos propostos por pelo Círculo de Bakhtin ${ }^{4}$ e Vygotsky e culmina na reflexão sobre possíveis encontros teóricos que possam nos guiar na análise do corpus proposta para esta investigação.

\subsection{A linguagem sob uma perspectiva sócio-histórica: o Círculo de Bakhtin}

O pensamento do Círculo Bakhtin foi essencial para a formulação de uma visão sócio-histórica sobre a linguagem. Tal visão surge a partir do embate das ideias de Volóchinov em contraposição às duas grandes concepçôes de linguagem que, segundo o autor, dominavam os estudos filológicos e linguísticos até então: o subjetivismo idealista e o objetivismo abstrato (VOLOCHINOV, 2017). A primeira dessas correntes é aquela que enxerga a linguagem como atividade mental: o que o falante pensa, constitui a fonte única e exclusiva da língua e dos fenômenos da linguagem (WEEDWOOD, 2002). Para essa corrente, a língua deve ser enxergada como uma atividade, um processo criativo que se forma por atos de fala individuais, sendo as leis linguísticas essencialmente leis individuais psicológicas. Além disso,

4 Grupo de intelectuais que envolvia, dentre outros, Mikhail Bakhtin, Valentin Volóchinov e Pavel N. Medvedev (FARACO, 2009). 
a língua, vista como um produto acabado, se apresentaria como uma criaçáo solidificada, inerte, isto é, como uma simples ferramenta.

Já a segunda corrente, o objetivismo abstrato, se baseia na ideia da língua como um sistema de regras acabadas, tal como a visão saussuriana, estruturalista, da língua como um sistema. Segundo Volóchinov, o estruturalismo acaba por seguir a tradiçáo filológica clássica, ao ignorar a fala, baseando-se na língua enquanto um constructo teórico e abstrato, homogêneo, impossível de verificação empírica (WEEDWOOD, 2002). Em termos amplos, a crítica de Volóchinov se centrava na visão da língua como um sistema imutável, na crença nas leis da língua como essencialmente linguísticas, na separação efetuada por essa visão entre o sistema linguístico e os valores ideológicos e, por fim, na crença nos atos de fala como reprodução de formas normalizadas (VOLÓCHINOV, 2017).

Em oposição a essas duas correntes, Volóchinov propóe que consideremos a língua como uma atividade social, visão que coloca em primeiro plano não o produto linguístico, o enunciado, mas sim o processo, a enunciação (WEEDWOOD, 2002). Para Volóchinov, o sistema linguístico é construído a partir de uma reflexão sobre a língua, uma vez que o locutor usa a língua para suas necessidades enunciativas concretas, sócio-históricas; isto é, a língua se constrói e se orienta no sentido da enunciação da fala. Sendo social, histórica, a lingua(gem) é também um constructo ideológico, já que, no seu uso prático, a língua é inseparável da ideologia (VOLÓCHINOV, 2017).

Além disso, a língua em sua totalidade concreta, viva, em seu uso real, tem a propriedade de ser dialógica (BAKHTIN, 2016; VOLÓCHINOV, 2017). Esta propriedade vai além do diálogo face a face e existe em todas as esferas da comunicaçáo humana. Para o Círculo de Bakhtin, todo discurso é, indiscutivelmente, ocupado e atravessado pelo discurso alheio; ou seja, o discurso de um está sempre atravessado pelo discurso de outrem (BAKHTIN, 2016; VOLÓCHINOV, 2017). A linguagem passa, entấo, a ser vista como o ponto de tensão e interação entre as vozes sociais. Para Volóchinov, a enunciaçáo e prática social sáo conceitos interligados, sendo o ato de enunciação, na verdade, uma forma de agir no mundo. Nas palavras do autor:

Todo enunciado, mesmo que seja escrito e finalizado, responde a algo e orientase para uma resposta. Ele é apenas um elo na cadeia ininterrupta de discursos verbais. Todo monumento continua a obra dos antecessores, polemiza com eles, espera por uma compreensão ativa e responsiva, antecipando-a etc.[...] (VOLÓCHINOV, 2017, p. 184-185).

A partir dessa compreensão, é evidente que os indivíduos não recebem a língua pronta para ser usada: é necessário que se penetre na corrente ininterrupta da comunicação verbal para despertar a consciência e começar a operar no mundo (VOLOCHINOV, 2017). Sendo assim, ao contrário das correntes examinadas anteriormente, a enunciação não pode, de modo algum, ser considerada como individual no sentido restrito do termo, náo podendo ser explicada a partir de 
condiçôes idealizadas psicofisiológicas do sujeito falante. De acordo com Volóchinov (2017, p. 200): "O enunciado é de natureza social".

Essa concepçáo coloca o centro organizador do processo linguístico, formador da consciência, no exterior, e não no interior: a língua, ou melhor, o uso da língua(gem), a enunciação, na filosofia da linguagem do Círculo e Bakhtin, passa a ser enxergada como o produto da interação entre dois indivíduos socialmente e historicamente organizados. De acordo com o Círculo de Bakhtin, nas práticas de uso da língua(gem), "pressupomos um certo horizonte social típico e estável para o qual se orienta a criação ideológica do grupo social e da época que pertencemos" (VOLOCHÍNOV, 2017, p. 205). Em suma: "A situação social mais próxima e o ambiente social mais amplo determinam completamente e, por assim dizer, de dentro, a estrutura do enunciado" (VOLOCHÍNOV, 2017, p. 206).

Por fim, acreditamos que qualquer prática educacional que considere a historicidade dos sujeitos nela envolvidos, não pode ignorar a problemática ideológica que a visão de linguagem do círculo de Bakhtin no traz (AMORIM, 2014). É necessário pensarmos nos alunos, em geral, e nos estudantes usuários do Moodle, em específico, como sujeitos históricos e sociais, que constroem significados por meio de usos situados da linguagem. Além disso, é necessária a consciência de que o Ambiente Virtual de Aprendizagem é mais uma esfera discursiva na qual circulam diversos textos e de que somente ao contextualizarmos as práticas de ensinagem poderemos auxiliar o aluno no desenvolvimento de uma significativa experiência educacional.

\subsection{Uma visáo vygotskyana sobre o processo de aprendizagem-e-desenvolvimento}

Para Vygotsky, é impossível a qualquer abordagem psicológica do ensino a resolução de problemas de aprendizagem se não levarmos em conta a relação entre o aprendizado e o desenvolvimento. Essa relação, segundo o autor, continuava obscura até o início do século XX, uma vez que as formulaçóes teóricas existentes eram vagas e, muitas vezes, contraditórias. Para confirmar tal afirmação, Vygotsky empreende uma análise crítica das três principais correntes vigentes procurando, assim, abrir espaço para a formulação de uma nova teoria que desse conta da relação entre desenvolvimento e aprendizagem (VYGOTSKY, 2007).

A primeira corrente analisada pelo autor centra-se no pressuposto de que os processos de desenvolvimento da criança sáo independentes da aprendizagem. Essa corrente admite que o desenvolvimento é um pré-requisito para a aprendizagem: isto é, se as funçôes mentais de uma criança não estiverem amadurecidas suficientemente a ponto de aprender um assunto particular, entâo nenhuma instrução se mostrará útil. Sendo uma teoria unilateral, teóricos afiliados a essa primeira corrente acreditavam no desenvolvimento como uma pré-condição da aprendizagem, mas nunca como resultado dela (VYGOTSKY, 2007). Já segunda grande corrente argumenta a completa identidade entre aprendizagem e desenvolvimento: aprendizagem é desenvolvimento (VYGOTSKY, 2007). Dessa forma, o desenvolvimento é enxergado como o simples domínio de reflexos condicionados. O principal risco 
dessa segunda posição é a redução do processo de aprendizagem à simples formação de hábitos.

Por fim, a terceira corrente analisada por Vygotsky objetiva a superar as posiçóes extremas sustentadas pelas outras duas simplesmente combinando-as. Para essa corrente, o desenvolvimento se baseia em dois processos distintos, mas relacionados, num movimento em que um polo influencia o outro: "de um lado a maturação, que depende diretamente do desenvolvimento do sistema nervoso; de outro o aprendizado, que é em si mesmo, também um processo de desenvolvimento" (VYGOTSKY, 2007, p. 90). Em outros termos, o processo de aprendizagem estimula e propicia o processo de maturaçáo. Entretanto, a crítica realizada pelo autor centra-se exatamente na crença de que as capacidades mentais funcionariam independentemente do material com o qual elas operam, uma vez que é assumido que toda aquisição de uma resposta em particular aumentaria diretamente e em igual medida a capacidade global de um estudante (VYGOTSKY, 2007).

Vygotsky sustenta a ideia de que a mente não é uma rede complexa de capacidades gerais - observação, atenção, julgamento etc. -, e sim um conjunto complexo de capacidades específicas, independentes, que se desenvolveriam também independentemente. Sendo assim, a aprendizagem é mais do que a simples aquisiçáo de capacidade para pensar: é a aquisição de capacidades diversas para se pensar sobre várias coisas (VYGOTSKY, 2007). Para Vygotsky, o desenvolvimento da consciência é o desenvolvimento de um conjunto de determinadas capacidades independentes ou de um conjunto de hábitos específicos, não de uma única forma local que propiciaria uma aprendizagem global.

A partir da crítica às três correntes citadas, o psicólogo apresenta, por fim, seu conceito de aprendizagem e a relação deste com o desenvolvimento da criança: "de acordo com Vygotsky, a aprendizagem se inicia muito antes da presença regular na escola, isto é, qualquer situação de aprendizado presenciada pela criança na escola tem sempre uma história prévia" (AMORIM, 2014, p. 361). Dessa forma, instituise uma inter-relação entre aprendizagem e desenvolvimento, ou aprendizageme-desenvolvimento, que se inicia desde os primeiros dias de vida da criança. Entretanto, não podemos enxergar esses dois polos como idênticos, uma vez que o aprendizado escolar introduz novos elementos à criança (VYGOTSKY, 2007).

Além disso, Vygotsky afirma que a aprendizagem deve ser combinada de alguma maneira com o nível de desenvolvimento da criança e, para tanto, é necessário atentarmo-nos para a determinação de pelo menos dois níveis de desenvolvimento: aquele pertencente à zona real de desenvolvimento e aquele pertencente à zona proximal de desenvolvimento (ZPD) (VYGOTSKY, 2007). O nível de desenvolvimento real seria o nível de desenvolvimento das funçôes mentais da criança que se estabeleceram como resultado de processos de desenvolvimento já completados, ou seja, pode ser medido por meio das tarefas que as crianças conseguem resolver sem o auxílio de terceiros (VYGOTSKY, 2007). Já a zona de desenvolvimento proximal, nas palavras do autor: 
define aquelas funçóes que ainda não amadureceram, mas que estão em processo de maturação, funções que amadurecerão, mas que estão presentemente em estado embrionário. (...) $\mathrm{O}$ nível de desenvolvimento real caracteriza o desenvolvimento mental retrospectivamente, enquanto a zona de desenvolvimento proximal caracteriza o desenvolvimento mental prospectivamente (2007, p. 98).

É a ZPD que nos permite delinear a capacidade futura imediata de desenvolvimento do educando em seu estado dinâmico, propiciando o acesso àquilo que está em processo de maturação. E para Vygotsky, assim como a linguagem para o Círculo de Bakhtin, o processo de aprendizado é essencialmente social: é a aprendizagem que desperta os processos internos do desenvolvimento que operam somente quando a criança interage com uma pessoa em seu ambiente, ou quando operam em conjunto com outras crianças. A partir daí, esses processos de aprendizado são internalizados e passam a fazer parte do desenvolvimento independente. De acordo com o autor (2007, p. 103):

Desse ponto de vista, aprendizado não é desenvolvimento; entretanto, o aprendizado adequadamente organizado resulta em desenvolvimento mental e póe em movimento vários processos de desenvolvimento que, de outra forma, seriam impossíveis de acontecer.

Afirma-se, por isso, que o aprendizado humano pressuponha de uma natureza social específica, configurando-se como um processo por meio do qual as crianças penetram semióticamente, através da linguagem, na vida intelectual daqueles que as cercam, isto é, passam a interagir socialmente no mundo pela/na linguagem (BAKHTIN, 2016; VYGOTSKY, 2007). Dessa forma, Vygotsky funda seu conceito sociocultural da aprendizagem numa abordagem sócio-histórica da mente, fato inédito no pensamento psicológico e pedagógico de entáo (WERTSCH, 1996). Isso se dá, principalmente, por meio da afirmação do autor de que as funções mentais superiores do indivíduo têm sua origem na vida social. Como já sinalizado, para Vygotsky, os fenômenos interpsicológicos derivam de fenômenos intrapsicológicos, isto é, sociais.

Para Moll e Greenberg (2007, p. 313), "uma das contribuições mais importantes da psicologia de Vygotsky é a proposição de que o pensamento humano deve ser compreendido em suas circunstâncias sociais e históricas concretas". $\mathrm{O}$ conceito de ZPD ilustra bem essa afiliação teórica ao demonstrar o nível de desenvolvimento possível de uma criança a partir de sua interação com outros seres e ambientes do mundo social. Segundo Valsiner (apud MOLL e GREENBERG, 2007, p. 320): a "ZPD pode ser construída não apenas pelos esforços propositais de quem instrui uma criança, mas também pela estruturação cultural do ambiente, de tal maneira que a criança em desenvolvimento é, a qualquer tempo, guiada por seu ambiente no uso de elementos ambientais que estáo correntemente na ZPD”. Em termos amplos, ao determinar o nível de desenvolvimento proximal de um educando, se não focalizamos as relaçóes sociais e o sujeito enquanto ser situado, podemos subestimar a riqueza de conhecimentos passíveis de serem construídos por determinados indivíduos. 


\subsection{Potencialidades de uma visáo sócio-histórica da linguagem e do processo de ensino-aprendizagem: o dialógico Círculo de Bakhtin-Vygotsky}

O Círculo de Bakhtin e Vygotsky compartilham ideias e uma visão sóciohistórica das relaçóes: seja enfocando a linguagem ou os processos de ensinoaprendizagem. Freitas (2005) relata que, apesar de objetivos diferentes - "Bakhtin procurando o desenvolvimento de uma teoria da linguagem e Vygotsky a fundação de uma nova psicologia" (AMORIM, 2004, p. 363) -, são diversos os pontos de encontro. Segundo essa autora, as principais possibilidades de encontro entre as teorias do Círculo e de Vygotsky estão ligadas a dois pontos básicos: o método dialético e sua visão das ciências humanas (FREITAS, 2005).

Epistemologicamente falando, o materialismo histórico-dialético, provindo, principalmente, dos ideais marxistas, está presente em ambos estudiosos como referencial teórico comum: ambos realizam um movimento de apresentação e crítica de correntes anteriores para, depois, sinalizarem os princípios teóricos que guiarão seus trabalhos. Apesar de ressignificarem o marxismo cada um a sua maneira, é comum a premissa de que todo fenômeno tem sua história e de que essa história é caracterizada por mudanças; os dois teóricos procuram observar um fenômeno em seu processo de formação e de desenvolvimento, seja esse fenômeno a linguagem ou a aprendizagem (FREITAS, 2005). Em outras palavras,

Pelas coordenadas dialéticas de seu pensamento, os dois autores não veem lugar para as dicotomias que isolam o fenômeno, fragmentando-o e imobilizando-o de maneira artificial. Tudo está em movimento. Todo movimento é causado por elementos contraditórios que coexistem posteriormente numa nova totalidade [histórica] (FREITAS, 2005, p. 300).

Além disso, nessas teorias, não há uma separação entre sujeito e história, pelo contrário, nos é apresentada uma perspectiva situada do homem, enraizada na história, que enxerga o sujeito como se constituindo nas relaçôes sociais (FREITAS, 2005): o Círculo de Bakhtin e Vygotsky desenvolvem suas teorias considerando os laços intrínsecos entre sujeito e objeto, propondo uma síntese dialética determinada pela cultura e pela história (SZUNDY, 2006). Freitas nos lembra ainda que, a partir do entendimento do homem como um sujeito social da/na história, acaba-se por considerar a cultura como o meio de existência por meio do qual a natureza humana é constituída em toda sua variedade. A partir dessa premissa,

Ambos não se detêm numa forma monológica de ciência que, buscando a explicação dos fatos, contempla os objetos mudos. Eles vão mais além numa proposta dialógica de ciência, em que o que se quer obter é a compreensão. O homem não pode ser explicado como fenômeno físico, como coisa, mas, sendo pessoa, tem que ser compreendido em suas açóes (FREITAS, 2005, p. 302).

Ao conceberem o homem como um ser histórico e como um conjunto das relaçóes sociais, o Círculo de Bakhtin e Vygotsky se propóem a investigar o modo como os fatores sociais podem modelar a mente e construir o psiquismo, sempre por meio da linguagem. Dessa forma, ambos autores constroem uma perspectiva 
semiológica. $\mathrm{O}$ signo, se considerado um produto social, tem função geradora e organizadora de processos psicológicos. Dessa forma, os teóricos soviéticos se voltam ao estudo do papel da mediação semiótica na constituição da consciência, no papel do outro e no dialógico como processos de interiorização (FREITAS, 2005). De acordo com Szundy (2006), tanto Vygotsky quando o Círculo de Bakhtin entendem que a consciência se constrói no processo de interação social semioticamente mediado.

Com efeito, os dois autores consideram que a consciência é constituída no social e relacionada a ele. Ela se constrói a partir das relaçôes que os homens estabelecem entre eles, em uma atividade sígnica, por meio da linguagem. É a linguagem, inclusive, que nos diferencia dos animais, para ambos os teóricos. "O homem ascende à sua humanidade, transforma-se de ser biológico em ser sóciohistórico no momento em que reflete a realidade objetiva de forma mediada, utilizando instrumentos psicológicos, os signos, na interação com os outros" (FREITAS, 2005, p. 303). Sendo assim, os autores dão grande importância para a interaçáo: não vista de forma restrita - eu com outro -, mas de forma ampla - eu com outros e com o meio social.

Outro ponto importante de encontro entre o Círculo e Vygotsky é o processo de internalizaçãos. Para Volóchinov (2017) são as estruturas sociais que, dialogicamente, constituem o homem enquanto cidadão. Esse processo, mediado pela linguagem, enxerga o sujeito como fruto das relaçóes sociais sendo modificado e, ao mesmo tempo, modificando o mundo pelas palavras. Já em Vygotsky (2007), a internalização é vista como a transformação dos processos interpessoais em intrapessoais, isto é, a reconstrução interna da atividade externa: "Para ele, a internalização implica uma reorganização das atividades psicológicas que se torna viável porque emerge de um terreno social, de uma interação com os outros por meio da linguagem" (FREITAS, 2005, p. 306).

Além disso, consideramos nesse trabalho a ideia de Zona de Desenvolvimento Proximal possível de ser inter-relacionada com o conceito de dialogismo bakhtiniano. A ZPD representa o processo pelo qual as crianças ascendem na vida intelectual e esse processo não se concretiza senão pelo emprego da linguagem enquanto instrumento dialógico, portanto, social, de interação. Freitas (2005) nos lembra que isso só é possível porque o sujeito vive em grupos e estruturas sociais e porque pode aprender juntamente a outros, por meio de sua relaçáo com eles. A ZPD representa, portanto, "uma dimensão dialógica do processo de construção do conhecimento" (FREITAS, 2005, p. 307). Freitas ressalta ainda que, como almejamos neste trabalho,

5 Há na literatura neovygotskyana uma extensa discussão sobre o conceito de internalização, visto, por vezes, como alinhado às ideias de participação, corporificação e negociação. Para este trabalho, consideramos as postulaçôes de Daniels (2003, p. 62-63), que defende a ideia da interiorizaçãoexteriorização. Em resumo, Daniels enxerga a interiorizaçáo como o movimento de reconstrução social da cultura e a exteriorizaçáo como criaçáo de artefatos que podem ser utilizados para transformar a cultura. 
Com base nessas ideias de Vigotski e Bakhtin pode-se pensar numa nova dimensão do espaço escolar que possibilite a manifestação da diferença dos modos e esquemas de construçáo do conhecimento, acompanhada de um trabalho pedagógico que se transforma numa ação compartilhada, num espaço de elaboração conjunta. Ao se valorizar essa interação dialógica, o aluno não é mais um agente passivo e receptivo, mas um sujeito que age e, pelo seu discurso, se faz ouvir, recriando-se no seio de outras vozes (2005, p. 308).

É esse potencial educacional apontado por Freitas que procuraremos considerar ao desenvolvermos apontamentos sobre a utilização do AVA como apoio ao ensino presencial na perspectiva sócio-histórica, objetivo de nosso trabalho.

\section{Metodologia da pesquisa}

Nesta breve seção, apresentaremos a metodologia de pesquisa utilizada neste artigo. Para tanto, inicialmente apresentamos o paradigma de pesquisa interpretativista-qualitativo, para, a seguir, descrevermos o contexto e os participantes da pesquisa, assim como os procedimentos de análise de dados.

\subsection{Tipo de Pesquisa}

A investigação nas Humanidades tem que dar conta da pluralidade de vozes em ação no mundo social e considerar que isso envolve questôes relativas a poder, ideologia, história e subjetividade (MOITA LOPES, 1994). A análise da implementação do AVA como apoio ao ensino presencial a partir de uma perspectiva sócio-histórica enquadra-se na modalidade de pesquisa qualitativo-interpretativista. Segundo Moita Lopes (1994), na visão interpretativista, o que é específico, no mundo social, é o fato de que os significados que o caracterizam são construídos pelo homem, que interpreta e reinterpreta o mundo a sua volta, fazendo assim, com que não haja realidade social única, mais várias realidades.

A metodologia qualitativa vem ao encontro do paradigma interpretativista por possibilitar a construção de conhecimento sobre questóes sociais complexas. Além disso, permite o exame de dados gerados a partir de um estudo particular, permitindo também a construçáo de um entendimento sobre a emergência e as características dos dados gerados. Em outros termos, a pesquisa qualitativa é "uma atividade situada que localiza o observador no mundo. Consiste em um conjunto de práticas materiais e interpretativas que dão visibilidade ao mundo" (DENZIN e LINCOLN, 2006, p. 17).

\subsection{Contexto e Participantes da Pesquisa}

Durante as reuniôes do colegiado do Curso Técnico em Informática para Internet de um campus de um instituto federal localizado na Baixada Fluminense do estado do Rio de Janeiro, começou-se a discutir o uso de um AVA como uma ferramenta de apoio às aulas presenciais. Nessa discussão, foi realizada a opção pela utilização da plataforma Moodle, que já estava disponível para na instituição. 
Foi acordado, então, que cada disciplina do curso contaria com uma sala de aula disponível no Moodle institucional, a partir da qual cada docente teria a autonomia para criar seu próprio conteúdo de apoio. Entretanto, foram convencionadas algumas questôes para que houvesse um padrão mínimo para o uso do AVA, sobretudo a preocupaçáo para que o docente não incluísse material que tomasse mais do que 20 minutos semanais de dedicação do aluno em cada disciplina, de forma a evitar sobrecarregá-lo com conteúdo online, uma vez que todo o conteúdo do Moodle era disponibilizado a título de complementaçáo.

Em relação aos participantes da pesquisa, as turmas com as quais os dados foram gerados eram compostas por um total de 41 alunos que haviam ingressado recentemente no primeiro período do curso. Demograficamente, se apresentaram indivíduos que se identificavam majoritariamente como do gênero masculino, sendo 29 alunos e 12 alunas. Todos os estudantes eram moradores da Baixada Fluminense. Também foi percebido que a maior parte dos alunos nunca havia experenciado práticas educativas em AVAs. Mais alarmante, era o fato de que a maioria dos educandos não possuía computador em casa e que alguns não tinham acesso frequente à internet. No entanto, o campus disponibilizava alguns computadores com acesso à internet em áreas como a biblioteca ou laboratórios para utilizaçáo dos alunos fora do horário da aula. Os professores das disciplinas, por sua vez, autores deste artigo, são docentes federais em regime de dedicação exclusiva há cerca de 4 anos, atuando no ensino básico e na pós-graduaçáo do referido instituto.

\subsection{Natureza e procedimentos da análise de dados}

Para a realização da pesquisa, optou-se por considerar as disciplinas Inglês Instrumental e Web Design. A escolha por essas disciplinas foi motivada pelo fato que as duas compóem o núcleo de linguagens do primeiro período do curso Técnico em Informática para a Internet. Enquanto a primeira trabalha com o ensino de língua estrangeira aplicado à área de informática, a segunda trabalha com linguagens de programação e criação gráfica, a partir do entrecruzamento de diversas modalidades e tipos de linguagens. Os dados foram gerados principalmente a partir de três fontes distintas: (a) a organização didático-pedagógica das duas disciplinas dentro do AVA; (b) a interação dos alunos e professores em fóruns e/ou outros recursos utilizados; e, (c) diário do pesquisador dos dois professores envolvidos na pesquisa.

A análise dos dados, por sua vez, foi realizada a partir dos pressupostos teóricos e metodológicos desenhados pela chamada Análise Dialógica do Discurso (ADD). De acordo com Brait (2004), a ADD procura, em sua constituição, compreender os processos de construçáo de sentidos e seus efeitos no mundo social. Para tanto, parte da ideia de que os sentidos se dão na interação social, sendo o sentido construído no diálogo entre sujeitos compreendidos como discursivos, históricos e culturais. Com efeito, na busca pela compreensão dos textos/discursos sob escrutínio, a ADD procura sinalizar a construção de sentidos a partir da análise de materialidades verbais e extraverbais, em sua combinação com o contexto mais amplo indiciado 
pelos traços de situaçôes particulares, isto é, pela relação dialógica do texto/discurso com formações sociais, discursivas e históricas.

Sobral e Giacomelli (2016) sinalizam ainda que a ADD parte de textos efetivamente construídos, procurando verificar de que modo os sujeitos realizam interaçóes a partir de gêneros do discurso e examinando as formas linguísticas em sua significação habitual. Em resumo, de acordo com esses autores,

Uma análise da ADD envolve, para dar conta dos dois componentes considerados - a língua e a enunciação -, os seguintes passos: descrever o objeto concreto em termos de sua materialidade linguística e de suas características enunciativas; analisar as relaçóes estabelecidas entre esses dois planos, o da língua (nível micro) e o da enunciação (nível macro); e, por fim, interpretar que sentidos cria a junção contextual da materialidade e do ato enunciativo (SOBRAL e GIACOMELLI, 2016, p. 1092).

Acreditamos, assim, que a ADD pode auxiliar no trabalho de criar inteligibilidade sobre os dados previamente gerados, ao oferecer ferramentas para a interpretação crítica e dialógica a partir de marcas linguístico-enunciativas e, consequentemente, sociais.

\section{Análise dos dados}

As disciplinas Inglês Instrumental e Web Design foram ofertadas durante um semestre letivo. Dessa forma, os AVAs foram sendo organizados ao longo do semestre. No AVA de Inglês Instrumental, encontramos uma parte geral e doze tópicos específicos. Na parte geral, foi disponibilizado, além de fóruns de "Notícias e Avisos" e "Dúvidas e Comentários", o Plano de Curso do semestre. Nos tópicos específicos, o conteúdo foi sendo construído a partir da experiência em sala de aula, dos conhecimentos prévios dos alunos e das respostas às tarefas avaliativas realizadas tanto no modo online quanto no espaço presencial. Assim, pode-se afirmar que o processo de construção da disciplina coadunou com uma abordagem sócio-histórica da aprendizagem (VYGOTSKY, 2007), uma vez que os saberes socialmente responsivos dos alunos foram considerados na organização de todo o curso. O último tópico dessa disciplina corresponde ao fórum de avaliaçáo do curso; as respostas a esse fórum serão discutidas posteriormente.

Em relação ao AVA de Web Design, uma primeira seção geral disponibilizou um fórum de avisos e materiais multimídia de apresentação da disciplina, além de questóes iniciais, como, por exemplo, um vídeo apresentando o que é Web Design e outro diferenciando tipos de programação. Outros oito tópicos específicos disponibilizavam conteúdos através de textos, vídeos, quizes e listas de exercícios. A última seção disponibilizava o fórum de avaliação da disciplina. Nesse sentido, o AVA dessa disciplina procurou, em uma perspectiva interacional, disponibilizar conteúdos em diferentes linguagens, considerando que os alunos aprendem de formas diversas no mundo social (VYGOTSKY, 2007). No entanto, é perceptível o pouco espaço dado à voz do aluno na plataforma, uma vez que ferramentas que envolvam interaçáo direta - fóruns, chats, wikis etc. -, não foram utilizadas ao longo 
do curso, com exceção do fórum de avaliação, o que, de certo modo, náo permitia a expressão da responsividade (BAKHTIN, 2016) discente.

$\mathrm{Na}$ primeira semana da disciplina Inglês Instrumental, foi disponibilizado um vídeo sobre a globalização e um artigo científico intitulado "Inglês em tempos de globalização: para além de bem e do mal". Além disso, foi disponibilizado também um fórum, "A língua inglesa e a globalizaçáo", que apresentava a seguinte questão "De que forma você sente o impacto da globalização e do inglês na sua vida diária?". Dessa forma, o conteúdo online da disciplina parece dialogar a sócio-história mundial com os conhecimentos prévios dos alunos, sobretudo ao situar responsivamente o ensino da língua inglesa num contexto de globalização, procurando entender as consequências dessa na vida dos alunos, o que coaduna com uma visão sócio-histórica da linguagem e da aprendizagem, especialmente no que tange à compreensão da linguagem como forma de interaçáo social, construtora de culturas, identidades etc. (VOLÓCHINOV, 2017; VYGOTSKY, 2007). A partir de tal temática, o professor pôde, em sala de aula, de acordo com seu diário do pesquisador, encaminhar uma discussão na tentativa de construção de posicionamento e conhecimento crítico por parte dos alunos: compreender os diferentes discursos que os/nos circundam e construir atos responsivos frente a eles (BAKHTIN, 2016) é engajar-se criticamente e socialmente (VYGOTSKY, 2007) no processo de ensinagem.

A participação no fórum online, no entanto, foi considerada baixa: apenas 8 alunos responderam à questão. Mais problemática ainda é a interação do professor com os alunos nesse fórum: em vez de promover interaçáo contínua ao longo da semana, o professor apenas respondeu aos alunos em um dia, no final da semana letiva, não incentivando a expressão da responsividade (BAKHTIN, 2016) discente. Dessa forma, a falta de interação do professor com os alunos pode ser um dos motivos que facultou a pouca participação de outros estudantes no fórum. As respostas registradas, no entanto, apresentam uma clara percepção dos alunos em relaçáo ao impacto da globalizaçáo e do inglês em suas vidas, como perceptível nos seguintes excertos: "A forma que sinto no impacto da Globalização, é ver que tudo que acontece em outros países pode também afetar no meu país, caso se a economia estiver ruim em certo país, o dólar ou o dinheiro aumenta e pode complicar numa venda/compra de uma certe emprega ou cliente." e "A língua inglesa está muito ativa no nosso dia a dia desde de filmes e series, músicas e expressôes como por exemplo a palavra spoiler, certo?".

Nas duas semanas seguintes, foram disponibilizados dois vídeos, produzidos pelo Instituto Federal de Roraima, com conteúdos dessa disciplina, a saber, o conceito de inglês instrumental e estratégias de leitura. Dessa forma, enxergase os vídeos como uma espécie de "par mais experiente" da teoria vygostkyana (VYGOSTSKY, 2007), que poderiam ajudar o aluno em seu processo de aprendizagem-e-desenvolvimento. No entanto, em relação a outros tipos de materiais, nas duas semanas foram disponibilizados (a) um teste de nivelamento, cuja a realização deveria ser em sala de aula e (b) um fórum com a pontuação de cada nível (básico, intermediário e avançado), devendo os alunos apenas sinalizarem 
em suas respostas o nível alcançado. Dessa forma, é perceptível uma visão do AVA como repositório de materiais, não sendo o instrumento realmente utilizado dentro de suas potencializadas metodológicas para o ensino da disciplina.

As seçóes da disciplina Web Design, por sua vez, foram segmentadas em observação ao plano de ensino da disciplina a partir de subseçóes que separam seus assuntos específicos. Nas duas primeiras seçôes, expunham conceitos sobre projeto de web design, sendo disponibilizados múltiplos modos de acesso à informação através do uso de vídeos, textos, páginas da internet para apreciação e lista de exercícios que o discente poderia fazer fora do horário da aula. Desse modo, entende-se o estudante como um agente multimodal, que navega por diferentes linguagens, enquanto ferramentas semióticas, na tentativa de construir suas diversas formas de aprendizagem (VYGOTSKY, 2007). A terceira seção do AVA traz conteúdos relacionados às ferramentas para a prática profissional de web design, acrescida de links para download dessas ferramentas de código aberto, o que proporcionou, posteriormente, em sala de aula, uma discussão sobre softwares aplicativos, pirataria, softwares de código aberto e a comunidades open source, de acordo com as anotaçóes do diário do professor.

Percebe-se, no entanto, como já sinalizado, a não disponibilização de instrumentos que permitissem a participação ativa do discente com o conteúdo online. Dessa forma, prevalece a visão do AVA como repositório de conteúdos, uma vez que os vídeos, links e textos disponibilizados poderiam, por exemplo, ter sido enviados aos estudantes por e-mail, não sendo necessário o uso do Moodle. Apesar disso, havia, por parte do professor, a tentativa de promover interação entre os conteúdos do AVA e a disciplina nos momentos presenciais semanais do curso: nas aulas, o professor retomava dialogicamente os tópicos disponibilizados, promovendo discussóes junto aos alunos sob os temas em voga. Dessa forma, houve uma tentativa de abordagem sócio-histórica e interacional do ensino-aprendizagem (VYGOSTKY, 2007), que, no entanto, se efetivou realmente apenas na sala de aula presencial a partir da interaçáo entre os próprios discentes e entre os discentes e professor (VOLÓCHINOV, 2017; VYGOTSKY, 2007).

No diário do observador dos dois professores sobre as semanas aqui analisadas, é perceptível um certo nível de descontentamento em relação à interação dos alunos com o AVA. No diário do docente de Inglês Instrumental, isso é sinalizado no enunciado "Na primeira semana, apesar da pouca participação no fórum, notei grande empolgação dos alunos com a utilização do AVA. Nas semanas seguintes, os alunos entraram pouco no ambiente, e, quanto eu pergunto se eles assistiram aos vídeos, eles dizem que não." Dessa forma, é perceptível que, enquanto novidade, o AVA foi adotado pelos alunos apenas durante a primeira semana. No entanto, passada a novidade, o acesso ao ambiente e ao material disponibilizado diminuiu. O mesmo cenário se repetiu na disciplina de "Web Design". De acordo com as anotaçóes deste professor, "A frequência dos estudantes no AVA foi diminuindo ao longo do semestre, o que já percebi na terceira semana da disciplina". Tais enunciados demonstram, em alguma instancia, problemas em relaçáo a utilizaçáo 
do AVA como apoio ao presencial ou ainda a dificuldade dos profissionais em inserir alunos provindos de realidades diversas numa experiência virtual de aprendizado.

$\mathrm{Na}$ quarta semana da disciplina Inglês Instrumental, novamente foi disponibilizado um vídeo do IFRO sobre estratégias de leitura, juntamente a um exercício sobre essas estratégias que deveria ser feito em casa e enviado ao sistema. Dos 41 alunos, 20 entregaram o exercício pelo ambiente. Nota-se, no entanto, que não houve correção dos exercícios e devolução aos alunos pelo sistema. $\mathrm{O}$ professor afirma, em seu diário, por meio do enunciado "Resolvi corrigir os exercícios em sala, pedindo que os alunos abrissem suas tarefas nos computadores do laboratório". Náo ter utilizado o AVA na correção dos exercícios, novamente demonstra uma visão do ambiente como repositório de conteúdos. A visão do ambiente como repositório é continuada nas duas semanas seguintes que apresentam mais dois vídeos sobre estratégias de leitura do IFRJ e materiais sobre a língua inglesa na área da informática com o rótulo "Material para sala de aula". Dessa forma, nessas semanas, o AVA funcionou como uma espécie de material didático que abarca textos e vídeos para que o aluno aprenda o conteúdo, o que pode demonstrar, inclusive, uma certa visão bancária (FREIRE, 2005) do processo educativo.

Nas próximas três seçóes da disciplina Web Design, a forma como foram disponibilizados os materiais permaneceu inalterada, havendo uma profusão de materiais multimídia, mas sem que fosse disponibilizado um instrumento para interação entre os discentes e entre discentes e professor. Desse modo, manteve-se uma visáo conteudista no uso da plataforma como repositório de materiais. As listas de exercícios foram, assim como nas semanas anteriores, disponibilizadas: cada seção apresentou uma lista de exercícios que abordava os tópicos da disciplina a partir de atividades de fixação. Os exercícios incluíam questóes de múltipla escolha com correção automática através da plataforma, assim como questôes discursivas, corrigidas, posteriormente, pelo docente, através do próprio Moodle. Dessa forma, apesar de, nas questôes de múltipla escolha manter-se uma visão tradicional da prática pedagógica, as questóes abertas e a correção pelo AVA possibilitavam a construção de uma prática diferenciada de aprendizagem, sendo o Moodle utilizado como instrumento mediador da aprendizagem dos alunos (VYGOSTKY, 2007). A participaçáo dos discentes nas listas de exercícios era obrigatória, sendo contabilizada no rol das avaliaçóes ao longo do semestre. Desse modo, a participação foi quase total, havendo poucos casos de alunos que deixaram de fazer alguma das listas no prazo estabelecido. Ao final da sétima seção, foi disponibilizado o resultado parcial do semestre com as notas e faltas dos alunos até então, o que sinaliza, novamente, a visão do Moodle como repositório de conteúdos.

$\mathrm{Na}$ sétima semana da disciplina Inglês Instrumental, foi disponibilizado um tipo diferente de vídeo; nesta semana, em vez de vídeos sobre inglês instrumental, foi disponibilizado material sobre a história da linguagem humana. Esse material foi escolhido, de acordo com o professor da disciplina em seu diário do pesquisador, devido ao tema dos textos que seriam trabalhados em sala de aula naquela semana. Dessa forma, esperava-se que o aluno, dialogicamente (BAKHTIN, 2016), construísse sentidos sobre os textos presenciais, dialogando seu conhecimento de 
mundo, com o conhecimento proposto pelo vídeo e o material de sala de aula. Além do vídeo, novamente o AVA é utilizado como repositório de conteúdos ao apresentar "Material para sala de aula". No tópico da semana seguinte, novamente o professor apresenta um vídeo com tema relacionado ao material a ser utilizado em sala de aula. Dessa vez, o assunto é a diferença entre vírus, worm e trojans, ameaças a sistemas informacionais.

No entanto, diferentemente das semanas anteriores, foi disponibilizado um fórum para que os alunos sinalizassem suas atitudes responsivas (BAKHTIN, 2016) em relaçáo a "Qual o assunto principal do vídeo?", "Quais as diferenças que você percebeu em relação às três ameaças à "Internet Security" apresentadas no vídeo?", "Assistir ao vídeo lhe fez repensar sobre a forma como você utiliza o seu computador? Por quê?" e "Você teve dificuldades na compreensão do vídeo? Por que?", enunciados presentes no AVA. A participação no fórum novamente foi pequena, tendo o professor sinalizado, 7 (sete) dias após o início do fórum, em uma postagem, a necessidade de participação dos alunos: "Estou aguardando a participação de vocês aqui! Vamos lá?!?”. Ainda assim, apenas 7 (sete) alunos participaram do fórum, não recebendo feedback do professor. Vale destaque, no entanto, a maior intimidade dos alunos com o ambiente, uma vez que, nesse fórum, são perceptíveis respostas que utilizam a inserção de imagens e formatação de texto, como o ilustrado pela figura abaixo.

Figura 1 - Resposta ao fórum da semana 8 .

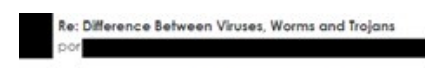

1 - Qual o assunto principal do video?

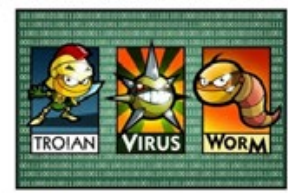

8: Um pequeno video para explicar a dilerença entre Vírus. Worm's e Covales de Trólo.

2.- Quais as diferenças que você percebev em relação às três ameaças à "Intemet Security" apresentadas no video? R: Elas sao uma das mais comuns no mundo da Internet. Virus é mais com um ao usuário simples, pois se anexa a um programa ou arquivo que permite que ele se espalhe de um computador para outro, deixando infecçঠes enquanto viaja. Vírus a um arquivo executável...So funciona se você abrito. Já os Worm's é semelhante ao Vírus, sua maior diferençca é que uma vez instalado, ele se auto-propaga independente de açăo humana. Já o Cavalo de Troia, se apresenta mulfo identico a programas e softwares originais. Porém, carregados de funçöes para exclusăo de arquivos, fotos, videos, imogens... Sistemal Porém, ndo se feproduzi, nem se mulfiplice.

3- Assistir ao video lhe fez repensar sobre a forma como você utiliza o seu computador? Por que?

R: No mav caso particularmente nảo. Pols já soffi com tals máwares, entảo já estou receoso com tá situaçăo.

4. Você teve dificuldades na compreensão do vídeo? Por que?

R: Sim. pos o locutor do video era um tanto "apressado", porém com algumas repetiçoes consegul compreander a lógica do video.

$\mathrm{Na}$ última semana desse mesmo curso, novamente foi disponibilizado um vídeo referente à temática a ser trabalhada no material de sala de aula: lugares estranhos para se visitar. Junto ao vídeo, foi aberto um fórum que questionava o lugar mais estranho que os alunos já visitaram e o motivo da estranheza nesse lugar. Apesar da proposta possibilitar uma visão sócio-histórica e contextualizada de 
construção de sentidos (VOLÓCHINOV, 2017; BAKHTIN, 2016) - percebida, sobretudo, pela forma como os alunos dialogaram a questão com sua realidade sócio situada -, novamente, o professor não interagiu com os alunos, náo dando feedback ou propondo maiores discussóes sobre as temáticas abordadas pelos alunos. Paradoxalmente, esse é o fórum que apresenta maior interação por parte dos alunos: foram 14 (quatorze) respostas à questão proposta. Ademais, mais uma vez, nessa semana, foi postado no AVA "Material para sala de aula". Por fim, é importante sinalizar que apesar da tentativa de maior interação entre os temas dos vídeos e os textos trabalhados em sala de aula, o professor enuncia, em seu diário, que "os alunos náo veem os vídeos. Por isso, eu acabo reproduzindo esses materiais no projetor no início das aulas."

O último tópico da disciplina Web Design consistiu em trechos de código que podem ser replicados da área de linguagem de programaçáo para web, com exemplos de páginas web e uma referência à biblioteca de software W3.css. Todo esse material foi disponibilizado para suprir os discentes com informaçóes que os apoiassem em seu projeto final da disciplina. Dessa forma, temos, novamente, o AVA sendo utilizado como repositório de conteúdo, de forma ainda mais explicita, uma vez que esses materiais estavam no Moodle apenas para download. Sobre essa disciplina, ainda é importante notar que todo o conteúdo do AVA, de acordo com o diário do pesquisador, foi escolhido a priori, no início do semestre letivo, sem considerar o conhecimento prévio dos estudantes, o seu nível de desenvolvimento e o seu potencial de aprendizagem o que vai de encontro a uma visão sóciohistórica da aprendizagem (VYGOSTKY, 2007). Ao longo do semestre, o professor apenas disponibilizava novos materiais para complementar os tópicos previamente definidos.

Em relação ao registro da linguagem utilizado nas duas disciplinas, percebese grande diferença. Na disciplina Inglês Instrumental há a tentativa de adequar a linguagem à um tom cotidiano, convidativo, para a potencialização da interação entre aluno e ambiente virtual: ao longo das seçôes, o professor apresentava enunciados como "Caro aluno...", "Dear ones", "Dear student", "Um grande abraço" e "Take care", que visavam a aproximar os estudantes do docente. Além disso, todos os textos eram construídos considerando o aluno como interlocutor direto da fala através do uso de recursos linguísticos como os pronomes "nós" e "você": "Nesta semana, vamos estudar a linguagem humana a partir de seu aspecto gramatical. Para isso, você deve assistir ao vídeo abaixo e levar para a sala de aula a apostila disponibilizada.”. Já na disciplina Web Design, é perceptível uma tentativa inicial de utilização de uma linguagem convidativa nos três primeiros tópicos em enunciados como "Você sabe o que é domínio? Você sabe o que é Hospedagem? Entenda a diferença entre dois serviços." e "Quer saber mais? Acesse a página registro.br para saber como registrar um domínio na internet.". No entanto, nas semanas seguintes essas interlocuçóes pararam, sendo apresentados apenas enunciados descritivos do material disponibilizado, como em "Série de vídeos sobre como utilizar o GIMP." e "Vídeo em inglês, legendas somente em inglês." A falta de 
uma linguagem que considere o aluno como interlocutor pode ser um dos motivos que levou à diminuição da interação do estudante com o AVA ao longo do semestre.

As duas disciplinas apresentaram, por fim, um fórum de avaliação. As questôes desse fórum foram construídas pelos professores em conjunto e disponibilizadas no AVA de cada uma delas, conforme figura abaixo, retirada da disciplina Web Design.

Figura 2 - Questões do fórum de avaliação final.

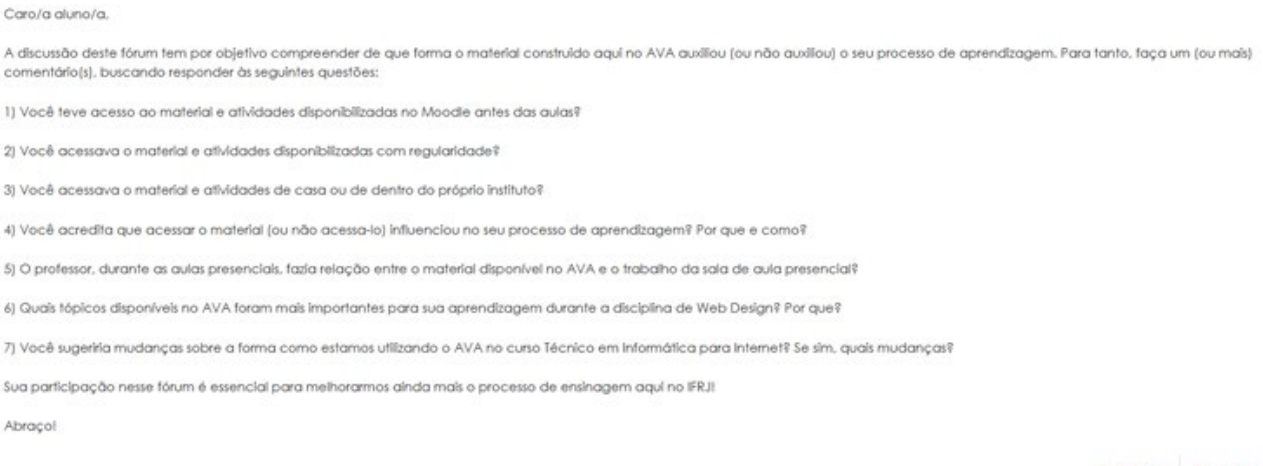

Justamente por terem construído as mesmas perguntas, variando apenas em questôes como a número 6 , que questiona em específico sobre a disciplina estudada naquela sala virtual, esse fórum náo abordava as especificidades da aprendizagem de cada matéria, focando-se em questóes mais gerais sobre a utilização do AVA. Isso levou alguns alunos a copiarem as respostas do fórum de uma disciplina para o fórum de outra. No entanto, mesmo com essa adversidade, os enunciados dos alunos trazem dados importantes para a pesquisa.

Nas respostas do fórum da disciplina de Web Design, a maior parte do corpo discente afirma ter tido acesso ao material e atividades disponibilizados no Moodle em antecipaçáo à aula que abordou aquele mesmo conteúdo, impressão não compartilhada pelo professor em seu diário de pesquisador. Uma parte menor dos discentes afirmou quase sempre ter tido o acesso antecipado. Além disso, a maior parte dos estudantes afirmou ter sempre acessado os materiais e atividades disponibilizados com regularidade. Apenas 3 alunos afirmaram que não acessaram o AVA com regularidade durante semestre. Dentre os motivos para a infrequência mais citados, os discentes alegaram que a participação "variava a depender de qual fosse disciplina", "falta de tempo" e "não possuir computador disponível em casa". No fórum da disciplina Inglês Instrumental, as respostas a essas primeiras questóes são, em geral, semelhantes. No entanto, algumas delas trazem novos dados à discussão: (a) alguns alunos sinalizaram problemas e dificuldades no acesso causados por motivos diversos como a demora em receber a senha de acesso ao AVA - "Sim, desde o início do curso porém alguns alunos que entraram ao longo das aulas e até 
mesmo alguns que já estavam desde o inicio demoraram a receber o login e senha do AVEA"; e, (b) alguns alunos afirmaram a falta de computador em casa, como já sinalizado - "Não, por falta de PC".

Em relação ao último tópico, o local de acesso à internet mais utilizado pelo corpo discente, a maioria afirmou ter acessado a plataforma predominantemente de suas residências, enquanto um número menor de estudantes afirmou ter acessado ao AVA predominantemente a partir dos laboratórios do instituto. Os motivos mais apontados para o acesso no instituto foram: "Não possuir computador em casa", como já sinalizado, e a dificuldade para organizar o próprio tempo de estudos quando no ambiente doméstico. A grande maioria dos alunos, nas duas disciplinas, acredita que o acesso à plataforma influenciou positivamente seu desempenho nos estudos durante o período letivo. Poucos alunos acreditam que houve uma influência apenas parcial. Além disso, a totalidade do corpo discente afirmou ter a percepçáo de que o professor da disciplina fez a adequada relaçáo entre o material disponível no AVA e o trabalho da sala de aula presencial.

Quanto aos tópicos mais citados no fórum da disciplina de Web Design conforme sua importância para a formação do aluno, foi considerado majoritariamente que os tópicos de referências e bibliografia foram os mais importantes para os discentes. Em seguida, tópicos com instruçóes para exercícios ou outras atividades em sala de aula e conteúdos em vídeo. Por último, foram esparsamente citados tópicos sobre conteúdo específicos da disciplina. Na disciplina de Inglês Instrumental, foram citados pelos alunos assuntos específicos da matéria, tais como as "estratégias de leitura". Importante notar, no fórum dessa disciplina, um enunciado de um aluno que diz que o assunto mais importante foi "As regras para como traduzir os textos"; paradoxalmente, essas regras não figuravam em momento algum da disciplina no AVA ou ainda em sala de aula, de acordo com o diário do professor. A compreensáo dos alunos do ponto mais importante da disciplina vai ao encontro de uma visão conteudista do ensino-aprendizagem, uma vez que, nas duas disciplinas, o "conteúdo" é o ponto mais sinalizado pelos discentes.

Ao final do fórum, quanto às sugestôes dos discentes para a melhoria da forma como foi utilizado o AVA como apoio às atividades presenciais, a sugestão mais mencionada na disciplina Web Design foi "acrescentar mais exercícios de múltipla escolha, como de provas e concursos", seguido de um pedido para "evitar usar o Moodle para questôes essenciais, pois há alunos sem internet em casa”. Uma aluna sinalizou a seguinte sugestão de mudança "Sim, eu acho que em algumas o material aqui no AVA fica muito massante, e fica complicado para estudar e compreender", o que denota o incomodo da estudante com a utilização do Moodle como repositório de conteúdos em massa. Já no fórum da disciplina Inglês Instrumental, surgiram sugestôes como "Atividades com mais freguência [sic] (exercício de fixação)" e "Por atividades das matérias para responder no AVA para estimular os alunos a estudarem e praticarem mais...”. Tais sugestôes nos permitem perceber que os alunos, em algum nível, estavam cientes da falta de mais instrumentos de interaçáo no AVA, uma vez que as sugestóes indicam pedidos de mais atividades práticas neste ambiente. 


\section{Consideraçóes finais}

A breve análise dos discursos do AVA, de professores e de alunos das disciplinas Inglês Instrumental e Web Design do Curso Técnico em Informática para Internet visou a refletir sobre a maneira pela qual as teorias sócio-históricas da linguagem, construída no interior do Círculo de Bakhtin, e da aprendizageme-desenvolvimento, proposta por Vygostky, foram ressignificadas, refratadas, na construção de uma nova proposta didática para o mencionado curso.

Em relação a esse processo de ressignificação, pode-se perceber que há, nas duas disciplinas, uma tentativa de se abordar a ensinagem a partir de uma perspectiva social, que considere o conhecimento prévio do aluno enquanto ser do mundo social, que dialoga e opina sobre diferentes saberes, construindo significados sobre diferentes temáticas e propostas. Isso fica mais evidente na disciplina de Inglês Instrumental, sobretudo pela abordagem de temas como globalização e linguagem, e pela presença massiva de fóruns, ainda que, por vezes, esses tenham sido pouco utilizados pelo docente responsável. No entanto, mesmo nesta disciplina, o que foi perceptível é a fricção entre uma educação tradicional, de cunho bancário, na qual o AVA é usado enquanto depósito de conteúdos, e práticas socialmente mais responsivas na atividade didático-pedagógica dos docentes.

Desse modo, entende-se que o ambiente e a própria prática pedagógica dos professores envolvidos devem passar por ressignificaçôes, de modo a permitirem a construção de um processo de aprendizagem sócio-históricamente situado. A experiência de proposiçáo da relação Moodle e sala de aula presencial, a utilização do AVA durante o semestre e posterior análise dos resultados, no entanto, pode trazer novos caminhos para a ensinagem dos saberes relacionados às duas disciplinas, permitindo um repensar e uma ressignificação notadamente necessária não apenas na construção dos materiais e atividades disponibilizadas no Moodle, mas também na própria prática de sala de aula.

Por fim, é importante sinalizar que a leitura aqui realizada se configura como uma apenas dentre as possíveis sobre a utilização do AVA como apoio à educação presencial. Fica, então, conforme os apontamentos de Bakhtin (2016), que nos guiou durante a leitura realizada, nossa voz enquanto pesquisadores, que, sendo precedida por outras nas quais nos embasamos de forma responsiva, espera também suscitar respostas ativas e, na esfera acadêmica, futuras investigaçóes sobre o tema, que podem dialogar com a necessidade de formação de professores para o trabalho com o AVA como apoio ao presencial ou ainda com a necessidade de se repensar o tempo de planejamento e dedicação do professor ao ambiente num contexto misto - virtual e presencial - de aprendizagem.

\section{REFERÊNCIAS}

AMORIM, M. A. de. Documentos oficiais, currículo e ensinagem de I/LE: possíveis (inter-)relações sócio-históricas. Trabalhos em Linguística Aplicada, Campinas, n(53.2): 357-380, jul./dez. 2014. 
BAKHTIN, M. Os gêneros do discurso. Trad. Paulo Bezerra. São Paulo: Editora 34, 2016.

BRAIT, B. Linguagem e identidade: um constante trabalho de estilo. Trabalho, Educaçáo e Saúde, 2(1), 185-201, 2004.

DANIELS, H. Vygotsky e a pedagogia. São Paulo: Edições Loyola, 2001.

DENZIN, N., LINCOLN, Y. A disciplina e a prática da pesquisa qualitativa. In:

DENZIN, N., LINCOLN, Y. (Orgs.). O planejamento da pesquisa qualitativa: teorias e abordagens. Porto Alegre: Artmed, 2006. p. 15-41.

FARACO, C. A. Linguagem e diálogo: as ideias linguísticas do círculo de Bakhtin. São Paulo: Parábola, 2009.

FREIRE, P. Pedagogia do oprimido. Rio de Janeiro: Paz e Terra, 2005.

FREITAS, M. T. de A. Nos textos de Bakhtin e Vygotsky: um possível encontro. In: BRAIT, Beth. (Org.). Bakhtin: dialogismo e construção do sentido. Campinas: UNICAMP, 2005, p. 295-314.

HUERTAS, A. Teaching and learning logic in a virtual learning environment. Logic Journal of IGPL, Oxford, v. 15, n. 4, p. 321-331, 2007.

MOITA LOPES, L. P. da. Pesquisa interpretativista em linguística aplicada: a linguagem como condição e solução. D.E.L.T.A. Vol. 10, no 02, p. 329-338, 1994.

MOLL, L. C.; GREENBERG, J. B. A criação de zonas de possibilidades: combinando contextos sociais para a instrução. In: MOLL, L. C. Vygotsky e a educaçáo: implicações pedagógicas da psicologia sócio-histórica. Porto Alegre: Artes Médicas, 1996, p. 314-339.

NICOLAIDES, C. SZUNDY, P. T. C. A 'ensinagem' de línguas no Brasil sob a perspectiva da linguística aplicada: um paralelo com a história da ALAB. In: GERHARDT, A. F. L. M.; AMORIM, M. A. de. CARVALHO, A. M. Linguística aplicada e ensino: língua e literatura. Campinas: Pontes, 2013, p. 15-46

SELIM, H. M. Critical success factors for e- -learning acceptance: confirmatory factor models. Computers \& Education, Maryland Heights, v. 49, n. 2, p. 396-413, 2007.

SOBRAL, A.; GIACOMELLI, K. Observações didáticas sobre a análise dialógica do discurso - ADD. Domínios de lingu@gem, v. 10, n. 3, 1076-1094, 2016.

SZUNDY, P. T. C. Scientific and spontaneous concepts, primary and secondary genres, behavioral and crystallized ideologies: possible interrelations and educational implications. The ESPecialist, vol. 27, no 2, 213-233, 2006.

VOLÓCHINOV, V. Marxismo e filosofia da linguagem. Trad. Sheila Grillo e Ekaterina Vólkova Américo. São Paulo: Editora 34, 2017. 
VYGOTSKY, L. S. A formação social da mente. Trad. José Cipolla Neto, Luis Silveira Menna Barreto, Solange Castro Afeche. São Paulo: Martins Fonte, 2007.

WEEDWOOD, B. História concisa da linguística. Trad. Marcos Bagno. São Paulo: Parábola Editorial, 2002.

WERTSCH, J. V. (1996). A voz da racionalidade em uma abordagem sociocultural da mente. In: MOLL, L. C. Vygotsky e a educação: implicaçóes pedagógicas da psicologia sóciohistórica. Porto Alegre: Artes Médica, 1996, p. 107-121. 